\title{
O registro da intervenção no prontuário pelo terapeuta ocupacional em um ambulatório infantojuvenil $^{1}$
}

\author{
Débora Cristina Pelissari ${ }^{\mathrm{a}}$, Marina Silveira Palhares ${ }^{\mathrm{b}}$

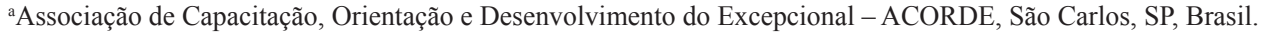

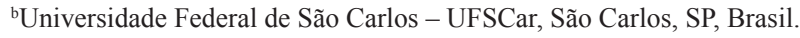

\begin{abstract}
Resumo: Objetivo: O estudo teve como objetivo descrever o que os terapeutas ocupacionais atuantes em serviço ambulatorial estão registrando em prontuário sobre o momento da intervenção. Procedimento metodológico: Para a coleta de dados, foi utilizado um check-list, que continha informações relativas ao momento da intervenção. Os prontuários analisados foram aqueles de pacientes que receberam atendimento terapêutico ocupacional no período de junho de 2012 a junho de 2013; deste período, selecionamos apenas aqueles que receberam alta, a fim de não trazer qualquer incômodo para a dinâmica do ambulatório, visto que os prontuários eram utilizados por diversos profissionais e estagiários do local. Foram analisados 269 registros de evoluções e 15 prontuários. Resultados: Pode-se constatar que as informações mais encontradas referentes às intervenções explanavam sobre o tipo de procedimento técnico utilizado na intervenção, estando presentes em 100\% dos prontuários. Observou-se que pelo menos um tipo de informação estava ausente dos prontuários, destacando-se as informações referentes ao histórico clínico e às recomendações de conduta terapêutica. Pôde-se verificar, também, que a narrativa livre foi o único método utilizado para o registro das intervenções. Conclusão: O estudo possibilitou maior aproximação com o tema - pouco abordado na literatura brasileira - e apontou para uma ausência de informações importantes nos prontuários, podendo sugerir que essa questão precisa ser mais bem trabalhada, estimulando a busca pela capacitação acerca do assunto. A pesquisa também forneceu conhecimentos que poderão orientar a prática dos terapeutas ocupacionais, possibilitando maior acuidade ao se realizarem registros em prontuários.
\end{abstract}

Palavras-chave: Terapia Ocupacional, Documentação, Registros Médicos, Assistência Ambulatorial.

\section{Record of the occupational therapist intervention on the medical record in a child and adolescent outpatient center}

\begin{abstract}
Objective: The study aimed to describe what the occupational therapists active in outpatient services register in the medical records regarding the intervention. Methodological procedure: A "check-list" containing information on the intervention was used for data collection. We analyzed records from patients who received occupational therapy services between June 2012 and June 2013, and selected only those who were discharged, in order to not disturb the outpatient clinic dynamics, since the records are used by many professionals and trainees at the site. We analyzed 269 records of evolutions, and 15 records. Results: Most of the information found was on the type of technical procedure used in the intervention in $100 \%$ of the records. It was observed that at least one type of information was missing from medical records, especially the information on the patient's medical history and therapeutics recommendations. Conclusion: The study allowed proximity with the subject rarely discussed in the Brazilian literature and may point to a lack of important information in the records, suggesting that this issue needs to be studied in more details, stimulating the search for capacitation on the subject. This research also provided knowledge that may guide occupational therapists enabling greater accuracy when performing patient records.
\end{abstract}

Keywords: Occupational Therapy, Documentation, Medical Records, Outpatient Assistance.

Autor para correspondência: Débora Cristina Pelissari, Universidade Federal de São Carlos, Rodovia Washington Luiz, Km 235, CEP 13565-905, São Carlos, SP, Brasil, e-mail: debora_pelissari@hotmail.com

Recebido em Jan. 20, 2014; $1^{\text {a }}$ Revisão em Mar. 31, 2014; $2^{\text {a }}$ Revisão em Abr. 30, 2014; Aceito em Ago. $14,2014$. 


\section{Introdução}

A qualidade dos registros efetuados em prontuário é reflexo da qualidade da assistência ofertada, podendo informar acerca do serviço prestado em saúde. A literatura levantada para este estudo é enfática ao dizer que o registro do profissional, escrito, é a única prova aceitável da intervenção no tratamento.

Esta pesquisa aborda a prática dos registros em prontuários, realizados por terapeutas ocupacionais atuantes em ambulatório infantil. O termo "registro", aqui utilizado, significa o ato de os profissionais anotarem suas intervenções.

Silva e Tavares Neto (2007, p. 114) ressaltam que "[...] registrar informaçóes é dever diário de todos os profissionais da área da saúde”.

É importante lembrar que o registro do profissional, escrito, é a única prova aceitável da intervenção no tratamento. Se algo não está escrito, aos olhos de quem consulta (por exemplo, pagadores ou jurados), é algo que não aconteceu (MATTHEWS; JABRI, 2004).

Pode-se afirmar que o sistema de saúde de um país é estabelecido graças ao que se tem documentado em um prontuário, uma vez que deste são extraídas as informaçôes sobre a saúde dos indivíduos que formam uma comunidade e uma nação (MARIN et al., 2003).

Para a revisão de literatura, foram utilizadas as bases de dados nacionais e internacionais: CAPES, LILACS, IBECS, MEDLINE, BIBLIOTECA COCHRANE E SCIELO, visto que a Biblioteca Virtual da Saúde (BVs) as considera fontes de informações da literatura científica e técnica das ciências da saúde em geral; realizou-se também a consulta em sites de editoras de periódicos de Terapia Ocupacional. A pesquisa abrange o período compreendido entre os anos 2000 e 2012 . Foram utilizados os seguintes descritores, selecionados a partir do banco de Descritores em Ciências da Saúde (DeCS), versão 2012 (BIBLIOTECA..., 2013): terapia ocupacional, documentação, registros médicos, assistência ambulatorial.

$\mathrm{Na}$ literatura nacional, até o momento, foi identificado um estudo que aborda a documentaçáo da Terapia Ocupacional. Trata-se de uma Pesquisa de Mestrado de Carla Panzeri, no ano de 2012, em que se investigou a prática da documentação clínica sob a ótica dos terapeutas ocupacionais. Também foi encontrado um capítulo do livro Prontuário do Paciente, de Ricarte e Galvão (2012), que debate, sem maiores aprofundamentos, o registro em prontuário na Terapia Ocupacional.

Não foram identificadas outras produçóes científicas que abordem especificamente a documentação das intervençóes da Terapia Ocupacional no Brasil; entretanto, tem sido observada a exigência cada vez maior das instituiçóes de saúde pela qualidade dos registros, impulsionada pelos sistemas de certificaçâo de qualidade.

Bertolli Filho (2006) evidencia a relevância dos prontuários quando afirma que os prontuários nos arquivos médicos afloram como peças preciosas que possibilitam confirmar saberes e desvelar sensibilidade, viabilizando novas possibilidades de apreensão da memória da Saúde.

O Conselho Federal de Fisioterapia e Terapia Ocupacional COFFITO divulgou, em 23 de maio de 2012, a resolução de número 415 , que dispóe sobre a obrigatoriedade do registro em prontuário pelo Terapeuta ocupacional.

Mezzomo (1991) denomina sistema de prontuário múltiplo como a situação em que as diferentes áreas possuem seus próprios prontuários e condena essa atitude, apontando a dificuldade do conhecimento global do paciente, a necessidade de mais espaço para armazenamento e o maior custo de manutenção.

O prontuário do paciente foi desenvolvido por médicos e enfermeiros para garantir que se lembrassem de forma sistemática dos fatos clínicos, de forma que todos os demais profissionais envolvidos no processo de atenção de saúde poderiam também acessar as mesmas informaçóes. Desta forma, localmente, o prontuário representa o mais importante veículo de comunicação entre os membros da equipe de saúde responsável pelo atendimento (SLEE; SLEE; SCHMIDT, 2000).

Segundo Foucault (1982), é a introdução dos mecanismos disciplinares no espaço confuso do hospital que vai possibilitar sua disciplinarização. Os doentes serão individualizados e distribuídos em um espaço onde possam ser vigiados e onde seja registrado o que acontece; ao mesmo tempo, se modificarão o ar que respiram, a temperatura do meio, a água que bebem, o regime, de modo que o quadro hospitalar que os disciplina seja um instrumento de modificação com função terapêutica. $\mathrm{O}$ autor também vem destacar que, com esta reorganização do espaço hospitalar, aparece uma série de registros que acumulam e transmitem informaçóes: o registro geral das entradas e saídas, em que se anota o nome do doente; o diagnóstico do médico que o recebeu; o registro do médico que manda anotar, durante a visita, as receitas e o tratamento prescritos, e o diagnóstico.

Tal transformação ocorre devido à transformação na compreensão da doença, que passa a ser entendida como um processo que necessita ser detalhadamente 
observado, através de um olhar minucioso e sistemático dos sintomas do paciente. Assim, passa a ser necessário o registro de cada encontro entre médico e usuário do serviço de saúde (NOVAES, 2003).

Em 1137, no Hospital São Bartolomeu, em Londres, já havia registros referentes aos internos para o tratamento (MARIN; MASSAD; AZEVEDO NETO, 2003).

Em 1580, na Itália, houve grandes alterações na administração dos hospitais e, em relação aos registros dos pacientes, passaram a ser obrigatórios os seguintes itens: prescriçấo médica individual, prescrição de regime alimentar, passagem de plantão e relatório de enfermagem de cada plantão (MEZZOMO, 1991).

No século XIX, Florence Nightingale, precursora da enfermagem moderna, já declarava a importância de haver os registros para a continuidade da assistência dos serviços de enfermagem (MARIN; MASSAD; AZEVEDO NETO, 2003).

Ainda no mesmo século, em 1877, o Hospital Geral de Massachussets, nos EUA, passa a arquivar os documentos clínicos e, em 1897, cria um Serviço de Arquivo Médico e Estatística - SAME (MEZZOMO, 1991).

Entretanto, em 1880, também nos EUA, Willian Mayo observou que os registros de todos os pacientes eram mantidos em um único documento, de maneira cronológica, o que dificultava o acesso a determinadas informaçóes específicas de cada paciente; portanto, em 1907, começou a utilizar o registro individual para cada paciente, que passa a ser arquivado separadamente, originando o prontuário médico, e mantendo-se a orientação cronológica que é utilizada até hoje (MARIN; MASSAD; AZEVEDO NETO, 2003).

Em 1928, foi fundada a Associaçáo Americana de Arquivo Médico e, em 1966, a Associação Brasileira de Arquivo Médico e Estatístico. No Brasil, a implantação do primeiro SAME ocorreu em 1943 no Hospital das Clínicas da Faculdade de Medicina da Universidade de São Paulo (MEZZOMO, 1991).

Possari (2007) afirma que decorridas as transformações na medicina, no século XX, e no modelo de atuaçáo em saúde, o conjunto de informações e impressos sobre o paciente se tornou objeto imprescindível a qualquer instituição.

Com o tempo, chegou-se ao consenso de quâo indispensáveis são os registros sobre o cuidado ao paciente e, assim, surgiu o prontuário conhecido hodiernamente. A denominação inicial de "Prontuário Médico" foi substituída por "Prontuário do Paciente", devido às transformações na relação médico-paciente, com ênfase na defesa dos direitos dos pacientes (NAVAES et al., 2011).

Estratégico para a decisão clínica e gerencial, para o apoio à pesquisa e para a formação profissional, atualmente o registro é considerado critério de avaliação da qualidade da prestação de serviço de saúde (VASCONSELOS; GRIBEL; MORAES, 2008).

Bacelar, Almeida e Andrade (2002) realizaram um estudo acerca das falhas comuns no uso do prontuário do paciente e encontraram erros e dúvidas habituais em seu uso. Tendo em vista a importância do prontuário e o grande número de irregularidades em seu uso, concluíram ser necessário que suas normas sejam divulgadas nas instituições por meio de educação contínua, sobretudo nos hospitais-escola.

Outra pesquisa realizada em um hospital, por Mesquita e Deslandes (2010), verificou que, na prática, o uso do prontuário está muito aquém do desejável. Dos 77 hospitais investigados, em 97,4\% verificou-se a inexistência da ficha de Terapia Ocupacional. Posteriormente, os autores descobriram que os profissionais mantinham agendas à parte dos prontuários, pois esses profissionais privilegiavam o "sigilo", justificado para preservar a individualidade. Os autores ressaltaram que os prontuários, enquanto relato de práticas dos profissionais de saúde, podem estar indicando o esgotamento de um modelo de prática de assistência modelada pela clínica convencional, assim como o esgotamento de um sistema de registros, cujos objetivos escapam à lógica da humanização proposta pela saúde pública e pelo SUS.

A documentaçáo incorreta pode influenciar o tratamento de uma forma negativa; por isso, é importante que os terapeutas ocupacionais saibam a importância e o significado de uma documentação apropriada (HEDBERG-KRISTENSSON; IWARSSON, 2003).

O conteúdo da documentação é regido por lei. O relatório escrito é o meio principal de justificar o tratamento adequado. Para garantir os direitos do paciente, o relatório deve ser factual, sem incluir julgamentos de valores que possam ser prejudiciais ao paciente. Além disso, o cliente tem o direito de saber o que consta nos registros e pedir para vê-los (MATTHEWS; JABRI, 2004).

Perinchief (2002) considera que, pela diversidade de exigências, muitos profissionais podem achar esta tarefa cansativa. Não há, na profissão, um método padrão ou exclusivo para documentar os serviços da TO (MATTHEWS; JABRI, 2004).

O prontuário é, também, um instrumento mediador na comunicação entre os profissionais, sendo necessário que a linguagem siga uma "ordem", 
ou seja, mostre-se padronizada, para que todos que tenham acesso aos registros consigam compreender o conteúdo anotado. Neste sentido, a Classificação Internacional de Funcionalidade (CIF), publicada pela Organização Mundial da Saúde em 2001, fornece conceito e linguagem comum para os envolvidos com o cuidado em saúde, podendo melhorar a comunicação através do estabelecimento de uma linguagem comum para a descrição da saúde e suas condiçóes correlatas (MÂNGIA; MURAMOTO; LANCMAN, 2008).

Youngstrom (2002 apud BUTTS; NELSON, 2007) argumentou que, nos últimos anos, tem havido uma constante transformação nos padrôes de prática de terapia ocupacional, incluindo a expansão dos locais de serviços e uma importância crescente atribuída ao valor terapêutico da ocupação na vida humana. Entretanto, segundo esta autora, tanto a documentação como a questão de uma terminologia uniforme não vêm acompanhando esta expansão.

O levantamento bibliográfico inicial realizado em bases de dados científicos, com publicaçóes nacionais e internacionais, mostrou uma pequena quantidade de publicaçôes em relação à documentação clínica em Terapia Ocupacional.

$\mathrm{Na}$ literatura estrangeira, principalmente em capítulos de livros ou documentos de associaçóes de classe, identificou-se, entre outras iniciativas: tentativa de padronização e estruturação nos processos de documentação (CLARK; YOUNGSTROM; AMERICAN..., 2008a); propostas de linguagem técnica com terminologia comum (CLARK; YOUNGSTROM; AMERICAN..., 2008b; CREEK, 2010); sugestóes de metodologia de registro (MATTHEWS; JABRI, 2004; RADOMSKI, 2005; PERINCHIEF, 2008).

Já na literatura nacional, não foram, até o momento, identificadas produçôes científicas que abordem especificamente a documentação das intervençóes da Terapia Ocupacional, exceto o estudo já citado de Panzeri (2013), sendo que tem sido observada a exigência cada vez maior das instituiçôes de saúde pela qualidade dos registros, impulsionada pelos sistemas de certificação de qualidade.

Bertolli Filho (2006) evidencia a relevância dos prontuários ao afirmar que:

No rol de documentos constitutivos dos arquivos médicos, afloram como peças preciosas que possibilitam fixar cenários, confirmar saberes e desvelar sensibilidade, enfim, viabilizar novas possibilidades de apreensão da memória da Saúde (BERTOLLI FILHO, 2006, p. 15).
Importa mencionar o grande número de variáveis envolvidas na prática profissional de terapeutas ocupacionais, o que dificultaria a análise dos dados obtidos. Por isso, sabendo-se que as práticas dos registros variam de acordo com os ambientes da prática profissional (CLARK; YOUNGSTROM; AMERICAN..., 2008a; PERINCHIEF, 2008), elegeu-se como fonte de dados para esta pesquisa os prontuários de terapeutas ocupacionais dentro de apenas um ambiente de atuação: o ambulatorial infantojuvenil.

É importante mencionar que o fato de existir recentemente uma publicação pelo COFFITO da resolução número 415/2012, que trata da documentação clínica, reforça a atualidade e a pertinência desta pesquisa.

Considera-se, ainda, que, na maioria dos trabalhos pesquisados sobre o atendimento ambulatorial em Terapia Ocupacional, não há a descrição e a caracterização do modo como essa prática é registrada, gerando uma lacuna que, se bem trabalhada, poderá ampliar a qualidade da atuação do terapeuta ocupacional, a comunicação destes com a equipe, bem como o processo de ensino e pesquisa. Portanto, diante do exposto e como forma de caracterizar os prontuários dos terapeutas ocupacionais, se faz pertinente perguntar: i) o que, especificamente, estes profissionais estão registrando em seus documentos, dentro do ambulatório em que atuam, e ii) qual o conteúdo desses registros. Observe-se que essa prática favorece o próprio profissional, bem como os demais envolvidos nesse processo: paciente, equipe, família, instituição e profissão.

Assim, a busca por produção de conhecimento que viabilize uma documentação em Terapia Ocupacional mais sistematizada e adequada à realidade brasileira pode contribuir para um aprofundamento da atuação na área com maior visibilidade das açôes do Terapeuta ocupacional e para a facilitação da comunicação entre os profissionais e, ainda, com as instituiçôes.

\subsection{Objetivos}

- Descrever o que está sendo registrado em prontuários da prática dos terapeutas ocupacionais atuantes em um ambulatório na área da infância e adolescência.

- Analisar os registros realizados no momento da intervenção.

- Verificar, à luz da literatura internacional e nacional, se os registros dos terapeutas ocupacionais estudados estão consonantes com os preceitos estabelecidos. 


\section{Método}

A amostra foi composta por 15 prontuários, sendo estes os que se encaixaram nos critérios de inclusão e exclusão da pesquisa. Em relação aos critérios de inclusão, a pesquisadora selecionou apenas os prontuários de pacientes que receberam atendimento no período de junho de 2012 a junho de 2013, e que já tivessem recebido alta, além de os registros terem sido realizados por TO já formado. Quanto aos critérios de exclusão, os prontuários eliminados do estudo foram aqueles de pacientes que receberam atendimento no período citado acima, mas que foram preenchidos por estagiários do ambulatório.

O presente estudo refere-se ao desenvolvimento de um estudo transversal, descritivo e exploratório, no qual utilizou-se a técnica de análise documental.

Em relação à classificação, conforme Sampiere, Collado e Lucio (2006), o estudo foi baseado na técnica de análise documental, porque foi feita uma análise cautelosa das fontes de informaçôes: os prontuários. Já a característica descritiva está ligada ao modelo transversal descritivo, que consiste em se apresentar e se descrever uma visão do estado de um objeto/contexto/situaçáo em determinado momento, e proporcionar sua descrição. Em relação ao caráter exploratório, este se deve ao fato de ser um estudo aplicado a um problema de pesquisa ainda pouco conhecido, que buscará conhecer um contexto, uma situação, um objeto.

Os terapeutas ocupacionais que tiveram os registros analisados foram previamente consultados, consentiram e autorizaram a pesquisa. Ao todo, foram seis profissionais e todos assinaram um Termo de Consentimento Livre e Esclarecido, permitindo a pesquisa sobre os seus registros em prontuários. Estes profissionais não são considerados participantes diretos da pesquisa, visto que o foco do estudo se volta para o conteúdo dos seus registros; assim, não se pretendeu fazer uma discussão através do perfil profissional de cada terapeuta, mas sim a partir do que foi encontrado ou não nos prontuários, de acordo com o que o checklist apontou como pertinente. Também optou-se por não identificar as áreas em que cada Terapeuta ocupacional atuava no ambulatório, como forma de não identificar o serviço, visando ao sigilo e às questóes éticas.

\subsection{Local}

O local escolhido configura-se como um ambulatório de média complexidade e atende especialmente aos municípios da região central do Estado de São Paulo.
Os atendimentos são realizados por docentes, profissionais de saúde da Unidade, voluntários já formados em Terapia Ocupacional e, principalmente, por estagiários dos cursos de saúde. Para este estudo, foram considerados apenas prontuários de profissionais, sendo excluídos da amostra os prontuários dos estagiários. O ambulatório em estudo, especificamente na área da Terapia Ocupacional, contava com profissionais voluntários ${ }^{2}$. O estudo de Panzeri (2013) aponta que o vínculo profissional menos formal pode influenciar negativamente a qualidade dos registros.

O ambulatório tem como missão formar e qualificar profissionais na área de saúde, desenvolvendo pesquisa científica e gerando tecnologia, além de prestar assistência qualificada e gratuita a todo cidadão dentro dos princípios do Sistema Único de Saúde, de forma articulada com a rede pública de saúde.

\subsection{Instrumento de coleta de dados}

Para a coleta de dados, foi utilizado um checklist, aprovado por juízes, que faz parte de um estudo desenvolvido por outro pesquisador deste grupo de pesquisa ${ }^{3}$. O instrumento de coleta dos dados foi criado com base em uma publicação da AOTA. Na referência mais atual - "Diretrizes para a Documentação em Terapia Ocupacional" -, os registros são descritos segundo as três áreas (categorias) do processo terapêutico: avaliação, intervenção e alta. Para cada tipo de categoria, recomenda quais informações são fundamentais para sua elaboraçáo com qualidade. Em relação à avaliação, inclui: registros referentes à triagem e aos relatórios de avaliaçáo e reavaliaçáo. Quanto à intervenção, inclui: plano de intervenção, notas de contato do serviço de Terapia Ocupacional, relatório de progresso e plano de transição (realizado quando o cliente precisa ser transferido para outro serviço de TO); em relação aos resultados, inclui o relatório de alta (CLARK; YOUNGSTROM; AMERICAN..., 2008a). Para o presente estudo, foram coletadas as informaçóes relativas apenas à intervenção.

\subsection{Aspectos éticos}

Foi garantido o anonimato da instituiçáo e elaborado um Termo de Consentimento Livre e Esclarecido para os profissionais autores dos registros dos prontuários do ambulatório. Não foi observado nenhum dano aos envolvidos direta e 
indiretamente na pesquisa, e não foi remunerada a participaçáo. Quanto ao manuseio dos prontuários, este foi realizado, exclusivamente, pela pesquisadora, em local definido pela instituição de origem dos dados, sem retirada do mesmo daquele espaço e sem a identificação dos pacientes ou terapeutas ocupacionais que fizeram as anotaçóes; apenas dados gerais, de interesse desta pesquisa foram coletados, de maneira a náo permitir outros usos a partir do manuseio dos prontuários, tratados como devidamente sigilosos.

\subsection{Procedimentos}

\subsubsection{Coleta de dados}

Antes de se iniciar a coleta de dados, foram estabelecidos os critérios de inclusão e exclusão da pesquisa.

A escolha de um período precisou ser determinada por alguns fatores, como o tempo disponível para a realização da pesquisa; serem prontuários já disponíveis no arquivo morto, ou seja, pacientes já fora do atendimento, e porque a pesquisadora necessitava travar contato com as profissionais que haviam atuado naquele período, considerando-se que a rotatividade de terapeutas ocupacionais do ambulatório é alta, devido aos profissionais serem voluntários. Estes fatores levaram a estabelecer um recorte de período que possibilitasse o acesso aos profissionais responsáveis pelos registros.

Antes de levantar os prontuários que se enquadravam nos recortes do estudo, a pesquisadora entrou em contato via e-mail com a supervisora do ambulatório, para que a mesma apontasse os nomes dos terapeutas ocupacionais atuantes na unidade. Após este contato inicial e de posse do endereço eletrônico de cada profissional do ambulatório, a pesquisadora solicitou, via e-mail, a autorização para a pesquisa e a assinatura do Termo de Consentimento Livre e Esclarecido.

Foram utilizados apenas os prontuários de crianças que não estavam em atendimento no momento da pesquisa, a fim de não trazer qualquer incômodo para os profissionais da equipe ou para as crianças e suas famílias, pois o manuseio destes documentos pela pesquisadora poderia interferir no andamento do serviço do ambulatório, visto que o ambulatório conta com diversos profissionais que fazem uso do prontuário antes e após suas intervençôes. Selecionados os prontuários, todas as anotaçôes foram coletadas.
A pesquisadora coletou os dados, analisando cada prontuário mediante a ordem e os critérios estabelecidos no instrumento de coleta. Os dados foram registrados pela pesquisadora diretamente no instrumento preparado para este fim, sendo uma cópia do instrumento para cada prontuário investigado.

\subsubsection{Análise de dados}

De acordo com os critérios de inclusão e exclusão desta pesquisa, foram analisados todos os prontuários que se enquadraram no recorte deste estudo, totalizando 15 prontuários, sendo analisados 269 registros de evoluçóes das intervençôes. É pertinente enfatizar que a amostra do estudo não permite generalizaçôes, mas uma aproximação com o tema escasso na literatura nacional.

Os dados foram organizados através de uma planilha eletrônica, do tipo Excel, para facilitar a descrição dos dados e sua análise. Como forma de se responder aos objetivos da pesquisa, a análise dos dados foi feita mediante a categoria intervenção.

A pesquisadora coletou os dados, analisando cada prontuário mediante a ordem e os critérios estabelecidos no instrumento de coleta. Os dados foram registrados pela pesquisadora diretamente no checklist preparado para este fim, sendo uma cópia do instrumento para cada prontuário investigado.

Foi analisado o que da categoria intervenção estava registrado, como, por exemplos: i) foram utilizados instrumentos padronizados específicos $\mathrm{da}$ Terapia Ocupacional ou são utilizados instrumentos padronizados interdisciplinares; ii) qual tipo de metodologia de registro foi utilizada: roteiro(s) pré-determinado(s) desenvolvido(s) na própria instituição, narrativa livre ou outro; iii) quais anotaçôes foram inseridas no registro, entre outros itens presentes no checklist. A análise dos dados forneceu respostas a essas perguntas, para que fosse possível entâo descrever o conteúdo encontrado nos prontuários.

\section{Resultados}

$\mathrm{Na}$ análise dos prontuários, quanto aos subtipos de registros utilizados para documentar a intervenção, a evolução é a forma mais usada para registrar a intervenção terapêutica ocupacional, estando presente em todos os prontuários analisados (100\%).

Em apenas um prontuário (6\%), foi observado o registro de plano de intervenção, sendo que este deveria indicar o caminho que o terapeuta iria utilizar 
para ajudar o paciente a atingir suas metas. O plano de intervenção estabelece frequência e a duração do tratamento (MATTHEWS; JABRI, 2004).

Na Tabela 1, está a distribuição do uso de subtipos de registros para a intervenção/acompanhamento.
A Tabela 2 apresenta quais informaçóes estavam presentes nos registros de intervenção/acompanhamento.

Pelo menos um tipo de informação relevante esteve ausente nos prontuários. O Gráfico 1 mostra a distribuição da ausência de cada informação.

Tabela 1. Distribuição do uso de subtipos de registros para intervenção/acompanhamento.

\begin{tabular}{lcc}
\hline & n (15) & $\%$ \\
\hline $\begin{array}{l}\text { Plano de Intervenção (realizado após avaliação para descrever objetivos pretendidos no } \\
\text { serviço de TO; pode estar junto ao impresso de avaliação ou constituir um documento } \\
\text { separado) }\end{array}$ & 1 & 6 \\
\hline $\begin{array}{l}\text { Nota de contato diário ou evolução (realizado para documentar cada atendimento } \\
\text { realizado a um grupo ou indivíduo) }\end{array}$ & 15 & 100 \\
\hline $\begin{array}{l}\text { Registro de progresso (realizado periodicamente para descrever a evolução do } \\
\text { cliente/paciente em um período de atendimentos; costuma ser utilizado para indivíduos } \\
\text { que são atendidos em grupos ou com grande número de atendimentos por semana) }\end{array}$ & 1 & 6 \\
\hline $\begin{array}{l}\text { Plano de transição (realizado quando o cliente/paciente precisa ser encaminhado a } \\
\text { outro serviço de TO) }\end{array}$ & 0 & 0 \\
\hline
\end{tabular}

Tabela 2. Informações presentes nos prontuários quanto aos registros de Intervenção.

\begin{tabular}{|c|c|c|}
\hline & $\mathbf{N}(15)$ & $\%$ \\
\hline $\begin{array}{l}\text { Informações para identificação do registro, como data, hora, nome do Terapeuta } \\
\text { Ocupacional responsável, formação e carimbo ou número de registro profissional }\end{array}$ & 14 & 93 \\
\hline $\begin{array}{l}\text { Informações para identificação da intervenção, como data, hora, local, quem estava } \\
\text { presente e Terapeuta Ocupacional responsável }\end{array}$ & 14 & 93 \\
\hline $\begin{array}{l}\text { Informações para identificação pessoal do cliente/paciente (nome, número de } \\
\text { prontuário, data de nascimento, gênero, escolaridade) }\end{array}$ & 13 & 86 \\
\hline Queixas e objetivos do cliente/paciente & 4 & 26 \\
\hline $\begin{array}{l}\text { Informações sobre condição de saúde e histórico clínico, como diagnósticos, medicação } \\
\text { em uso, precauções e contraindicações }\end{array}$ & 3 & 20 \\
\hline Informações sobre objetivo pretendido com a intervenção & 11 & 73 \\
\hline $\begin{array}{l}\text { Informação sobre o tipo de procedimento técnico utilizado, como treino de atividade de } \\
\text { vida diária, confecção de equipamento de tecnologia assistiva, orientação ao cuidador, } \\
\text { uso de técnica de estimulação visual, entre outros. }\end{array}$ & 15 & 100 \\
\hline
\end{tabular}

Descrição detalhada das atividades realizadas, informando os materiais, as diferentes tarefas que constituem a atividade, modificações propostas, forma de execução, entre 6 outros

Informações objetivas sobre a participação do cliente/paciente na atividade, como número de vezes que conseguiu executar uma tarefa específica, quantidade de auxílio necessária, tempo de permanência conseguido, se apresentou choro ou outros aspectos

"observacionais" de comportamento, entre outros

Informações subjetivas sobre a participação do cliente/paciente na atividade, se demonstrou satisfação ou descontentamento, impressões sobre aspectos emocionais

Análise do resultado da intervenção, se conseguiu ou não atingir o objetivo proposto

6

Recomendações de conduta terapêutica, se mantém ou não o número e tipo de atendimento determinado. 


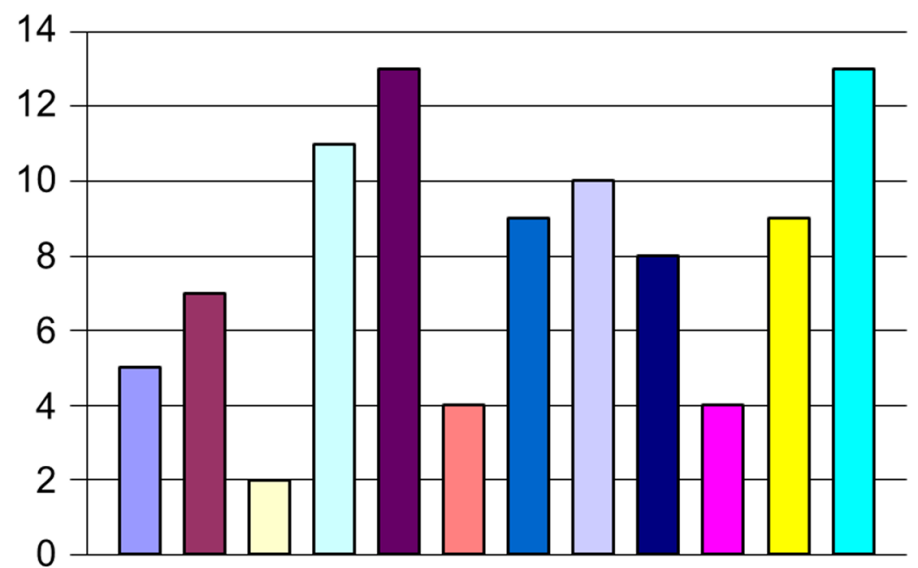

\begin{tabular}{l}
\hline Informações para identificar o \\
registro \\
Informações para identificar a \\
intervenção \\
Informações para identificação \\
pessoal do paciente \\
$\square$ Queixas e objetivos do paciente \\
घ Informações sobre condição de \\
saúde e histórico clínico \\
$\square$ Objetivo pretendido com a \\
intervenção \\
$\square$ Informação sobre tipo de \\
procedimento técnico utilizado \\
$\square$ Descrição detalhada da atividade \\
Informações objetivas sobre a \\
participação do paciente \\
$\square$ Informações subjetivas sobre a \\
participação do cliente \\
$\square$ Análise do resultado da \\
intervenção \\
$\square$ Recomendações de conduta \\
terapêutica
\end{tabular}

Gráfico 1. Informações ausentes nos prontuários quanto aos registros de Intervenção.

\section{Discussão}

Os dados alarmantes referentes à ausência de informaçóes quanto ao plano de intervenção refletem a necessidade da criação de espaços de discussão dentro dos serviços de saúde, visando à orientaçáo para a equipe e a instituição quanto ao registro apropriado das açôes profissionais, enfatizando que, dessa forma, se garante o respaldo ético e legal frente aos Conselhos, às Associações de Classe e à Justiça, e ainda garante a continuidade e a qualidade da assistência. A ausência de registro do plano de intervenção pode levar a uma falta de clareza para o profissional sobre sua própria ação, bem como pode dificultar a comunicação com a equipe e com a família ou os responsáveis pelo paciente.

O Ministério da Saúde aponta que o projeto terapêutico (ou plano de intervenção) ajuda na compreensão e no sucesso do tratamento, no sentido de reforçar e aprimorar as opçôes na abordagem da sequência saúde/doença/reabilitação (BRASIL, 2004).

A recente resolução 415/2012 do órgão fiscalizador da profissão (BRASIL, 2012) dispóe em seu sexto artigo que o plano terapêutico ocupacional deve conter a descrição dos procedimentos terapêuticos ocupacionais propostos, relatando os recursos, os métodos e as técnicas a serem utilizados, e o(s) objetivo(s) terapêutico(s) a ser(em) alcançado(s), bem como o quantitativo provável de atendimento.

Poder-se-ia levantar a hipótese de que o profissional mantenha suas anotaçóes ou registros em outros suportes ou que seja uma preferência do profissional em não manter essas informaçóes em prontuário multidisciplinar, optando por anotar em cadernos pessoais. Esta investigação náo foi realizada na presente pesquisa. Cabe aqui apenas registrar o que foi encontrado e apontar a necessidade de novas investigaçôes e açôes que possam sanar este problema.

De acordo com Matthews e Jabri (2004), para aqueles que atuam em equipe multi/interdisciplinar, o prontuário é a maior via de comunicação entre as diversas áreas, além de poder divulgar o trabalho e favorecer o reconhecimento da profissão.

Nos prontuários aqui estudados, o formato de registro era o manuscrito, em papel, formulários ou folhas brancas pautadas, tamanho ofício, padronizadas, com a identificação do ambulatório, sendo as anotaçóes registradas a próprio punho, em caneta azul. Verificou-se que, nos 269 registros analisados, todos estavam legíveis e sem rasuras. Este dado extremamente positivo merece destaque, quando comparado com alguns estudos que apontam aspectos negativos quanto ao formato manual da documentação, visto que a ilegibilidade pode comprometer todo o processo de atenção em saúde (BACELAR; ALMEIDA; ANDRADE, 2002).

No ambulatório em que a presente pesquisa foi realizada, todos os profissionais anotam no mesmo prontuário e as anotações são mantidas juntas, sendo os prontuários do tipo multi/interdisciplinar.

Mezzomo (1991) também defende que os prontuários que são mantidos juntos aos de outras 
áreas favorecem o reconhecimento total do paciente, além de economizar espaço e custo de manutençáo.

Quanto ao que diz respeito às informaçóes presentes nos prontuários em relação à intervençáo, na maioria dos prontuários constavam informaçôes que identificavam o registro, o sujeito e a intervenção, contendo: data, nome do terapeuta ocupacional responsável, formação e carimbo ou número de registro profissional. Em todos os prontuários, estavam presentes informaçóes quanto ao tipo de procedimento técnico utilizado. Informações, como a descrição detalhada da atividade em suas diferentes tarefas e partes que a constituem, não foram encontradas, uma vez que este tipo de anotação faz parte do raciocínio clínico do terapeuta ocupacional; sugere-se que não sejam, portanto, registros necessários em um prontuário multidisciplinar.

Em relação aos objetivos pretendidos com a intervenção, estes foram mais registrados (11 prontuários) do que os objetivos e queixas do paciente em si, que foram encontrados em apenas quatro prontuários. Esse dado faz pensar que o sujeito não está sendo protagonista do seu próprio tratamento e história, o que aponta para uma conduta dos terapeutas em que os problemas não são identificados junto com o paciente, fugindo-se, assim, da ideia proposta pelo SUS da clínica ampliada, que propóe considerar o doente como sujeito, no sentido de que ele tenha mais autonomia em relação à sua doença e ao seu tratamento.

Também se pode considerar que as informações quanto às queixas e aos objetivos sejam anotadas somente na avaliação, não sendo mais documentadas em outros momentos do tratamento, visto que os dados deste estudo apontam que tais informaçóes estão majoritariamente constadas na avaliação do processo terapêutico e não na intervenção.

Allen et al. (1989) apontam que as percepçôes de questóes relacionadas à profissão podem sofrer influências de motivos inconscientes, decorrentes de pensamentos ou emoçóes. As impressóes objetivas sobre a participação do paciente na atividade - como número de vezes que conseguiu executar uma tarefa específica, quantidade de auxílio necessária, tempo de permanência conseguido, se apresentou choro ou outros aspectos "observacionais" de comportamento, entre outros - talvez por serem mais detalhistas, foram a minoria, uma vez que, para o profissional, podem ser mais trabalhosas e requerer mais tempo para o registro. De acordo com Sames (2005), é primordial que a informação objetiva relatada na documentação seja nitidamente diferente da informação subjetiva. A autora cita um exemplo:
Se um profissional diz que um cliente parecia deprimido, esta é uma declaração subjetiva. É uma conclusão tirada a partir das observações do profissional. Para fazer uma declaração objetiva o profissional deve descrever o que foi observado ou escutado que logicamente levaria à conclusão de que o cliente parecia deprimido. Por exemplo, o profissional poderia dizer: A cliente olhou para o chão durante toda a sessão. Ela ficava inclinada para frente em sua cadeira, respondia as perguntas com palavras monossilábicas e náo iniciava qualquer conversa com seus colegas (SAMES, 2005, p. 411).

Quanto às impressóes que os profissionais tiveram do paciente ao final da intervenção, foram observados mais registros quanto às impressóes subjetivas do paciente, nas quais eram descritos aspectos emocionais, satisfação ou descontentamento, e a participação do paciente de modo geral.

Nota-se que as informaçóes quanto ao tipo de procedimento técnico utilizado no atendimento estavam presentes em todos os prontuários, por serem informaçóes básicas e que compóem o linguajar diário do terapeuta ocupacional; supóe-se que o registro das mesmas expóe objetivamente a ideia do que ocorreu no atendimento de modo geral. Porém, de acordo com Sames (2005), as evoluções devem incluir mais de uma lista de atividades que o paciente tenha realizado durante a sessão. $\mathrm{O}$ leitor daquele prontuário desejará saber como o desempenho do cliente se modificou desde a última sessão de tratamento e/ou quais as melhorias funcionais.

A análise do resultado da intervenção foi encontrada em apenas seis prontuários. Nessa informação, era documentado, sucintamente, de que maneira o objetivo proposto foi atingido e/ou se o paciente conseguiu realizar pelo menos parte dos objetivos. Quanto às recomendaçôes de conduta terapêutica, apenas em dois prontuários estas informaçôes foram observadas, o que inviabiliza a comunicação entre a equipe, para a qual serve o prontuário, além da omissão de informaçóes pertinentes, podendo gerar problemas legais para o profissional e/ou a instituição.

Além da resolução 415/2012, existem outras resoluçôes do COFFITO que, embora não explorem muito o conteúdo das informaçóes que devem constar nos registros, apontam de forma breve o que deve estar presente. Referente à especialidade de saúde mental, a resolução 408/2011 do COFFITO recomenda o registro e a guarda da evolução clínica e de relatórios. A resolução 405/2011, referente à Terapia Ocupacional em acupuntura, e a 407/2011, sobre saúde da família, apontam que são necessários os registros das consultas, da avaliação, do diagnóstico, 
do prognóstico, do tratamento, da evoluçáo, das intercorrências e da alta do serviço. Já a 406/2011, sobre a especialidade em contextos sociais, refere que devem ser anotados os dados dos sujeitos e elaborar encaminhamentos necessários, sem maiores aprofundamentos.

Toda documentação clínica deve ser feita obedecendo aos padrōes da instituição, bem como aos padrões estabelecidos pela profissão, como afirma Perinchief (2002), lembrando-se de que as práticas da documentação variam de um ambiente para outro. Às vezes, são diferenças que estão definidas pela política pública ou pela preferência do ambiente por tal prática.

Em relação à linguagem utilizada nos registros, o terapeuta ocupacional deve fazer anotaçóes claras, legíveis e coesas, com terminologia da profissão; essas normas estão na resolução 415/2012, mas esta não traz um referencial específico para tal terminologia.

A Pesquisa de Mestrado de Panzeri (2013) sobre a percepçáo que os terapeutas ocupacionais têm sobre a documentação clínica mostrou que os participantes daquele estudo consideraram que o tempo é o maior dificultador para o registro em prontuário, sendo o item mais citado como "empecilho" para o registro.

De acordo com Sames (2005), há dois pontos crucias que devem ser considerados quanto à documentação: i) as pessoas criam uma impressão do profissionalismo e da inteligência ao ler o que um profissional escreve, e ii) o que ele escreve pode ser usado como evidência em um processo judicial, quer a pessoa esteja em julgamento ou não (SAMES, 2005).

Espera-se que, através deste estudo, o prontuário seja visto como valor documental, ético e comunicativo, tornando-se um acervo para análise dos discursos dos profissionais da saúde e uma fonte de acesso às práticas e aos conhecimentos.

\section{Considerações finais}

Destacou-se, nesta pesquisa, a ausência de algumas informaçôes pertinentes nos prontuários. Espera-se que este estudo, juntamente com a publicação da recente resolução 415/2012 do COFFITO sobre os aspectos relacionados à documentação, estimulem os terapeutas ocupacionais a investirem na melhoria da qualidade dos relatos, para que sejam mais bem elaborados e mais completos, favorecendo a comunicação entre a equipe e possibilitando a promoção do serviço e a divulgação da Terapia Ocupacional.

A pesquisa pôde coletar dados que possibilitaram dar início a uma temática tão pouco abordada em nossa literatura nacional, fornecendo subsídios para elaboração de registros com mais conteúdo e qualidade, tendo em vista as finalidades e utilidades que cabem ao prontuário, destacando-se as questóes éticas, legais e judiciais.

O tamanho da amostra náo permite generalizaçóes, mas uma aproximaçáo do problema. Sugere-se que outras investigaçóes possam ampliar a legitimidade do estudo, com outros ambulatórios ou até mesmo em outros locais de atuaçấo do Terapeuta ocupacional, para assim se obter um panorama geral da qualidade e do conteúdo da documentação clínica na área. Estudos longitudinais também poderão permitir observar a evolução dos registros no tempo.

\section{Referências}

ALLEN, C. et al. A medical review approach to medicare outpatient documentation. The American Journal of Occupational Therapy, New York, v. 43, n. 12, p. 793800, 1989. http://dx.doi.org/10.5014/ajot.43.12.793. PMid:2694841.

BACELAR, S.; ALMEIDA, W. M.; ANDRADE, G. M. Falhas e dúvidas comuns no uso do prontuário médico do paciente. Brasília Médica, Brasília, v. 39, n. 1-4, p. 42-51, 2002.

BERTOLLI FILHO, C. Prontuários médicos e a memória da saúde brasileira. Boletim do Instituto de Saúde, São Paulo, n. 38, p. 12-15, 2006.

BIBLIOTECA VIRTUAL DA SAÚDE - BVS. Descritores em Ciências da Saúde - DeCS. Disponível em: <http://decs.bvs.br>. Acesso em: 18 jun. 2013.

BRASIL. Ministério da Saúde. Secretaria Executiva. Núcleo Técnico da Política Nacional de Humanização. Humaniza SUS: prontuário transdisciplinar e projeto terapêutico. Brasília, DF, 2004. (Série B. Textos Básicos de Saúde).

BRASIL. Conselho Federal de Fisioterapia e Terapia Ocupacional - COFITO. Resolução no 415, de 19 de maio de 2012. Dispóe sobre obrigatoriedade do registro em prontuário pelo terapeuta ocupacional, da guarda e do seu descarte e dá outras providências. Diário $O f$ cial [da] União, Brasília, DF, 23 maio 2012. Disponível em: <http://www.coffito.org.br/publicacoes/pub_view. asp? $\operatorname{cod}=2257 \&$ psecao=9>. Acesso em: 2 jun. 2012.

BUTTS, D. S.; NELSON, D. L. Agreement between occupational therapy practice framework classifications and occupational therapists' classifications. The American Journal of Occupational Therapy, New York, v. 61, n. 5, p. 512-518, 2007. http://dx.doi.org/10.5014/ ajot.61.5.512. PMid:17944288.

CLARK, G. F.; YOUNGSTROM, M. J.; AMERICAN OCCUPATIONAL THERAPY ASSOCIATION COMMISSION ON PRACTICE - AOTA. Guidelines for documentation of Occupational Therapy. The Ame- 
rican Journal of Occupational Therapy, New York, v. 62, n. 6, p. 684-690, 2008a. http://dx.doi.org/10.5014/ ajot.62.6.684. PMid:19024745.

CLARK, G. F.; YOUNGSTROM, M. J.; AMERICAN OCCUPATIONAL THERAPY ASSOCIATION COMMISSION ON PRACTICE - AOTA. Occupational therapy practice framework: domain and process. The American Journal of Occupational Therapy, New York, v. 62, n. 6, p. 609-639, 2008b.

CREEK, J. The core concepts of Occupational Therapy: a dynamic framework for practice. London: Jessica Kingsley Publishers, 2010.

FOUCAULT, M. O nascimento do hospital. In: FOUCAULT, M. Microfísica do poder. Rio de Janeiro: Graal, 1982. p. 99-111.

HEDBERG-KRISTENSSON, E. H.; IWARSSON, $S$. Documentation quality in occupational therapy patient records: focusing on the technical aid prescription process. Scandinavian Journal of Occupational Therapy, Oslo, v. 10, n. 2, p. 72-80, 2003. http://dx.doi. org/10.1080/11038120310009434.

MÂNGIA, E. F.; MURAMOTO, M. T.; LANCMAN, S. Classificação Internacional de Funcionalidade e Incapacidade e Saúde (CIF): processo de elaboração e debate sobre a questão da incapacidade. Revista de Terapia Ocupacional, São Paulo, v. 19, n. 2, p. 121-130, 2008.

MARIN, H. F.; MASSAD, E.; AZEVEDO NETO, R. S. Prontuário eletrônico do paciente: definições e conceitos. In: MASSAD, E.; MARIN, H. F.; AZEVEDO NETO, R. S. O prontuário eletrônico do paciente na assistência, informação e conhecimento médico. São Paulo: Editora do Autor, 2003. p. 1-20.

MATTHEWS, M. M.; JABRI, J. L. Documentação dos serviços de Terapia Ocupacional. In: PEDRETTI, L. W.; EARLY, M. B. Terapia Ocupacional: capacidades práticas para disfunçóes físicas. São Paulo: Roca, 2004. p. $98-107$.

MESQUISTA, A. M. O.; DESLANDES, S. F. A construção do prontuário como expressão da prática dos profissionais de saúde. Saúde e Sociedade, São Paulo, v. 19, n. 3, p. 664-673, 2010.

MEZZOMO, A. A. O prontuário do paciente. In: MEZZOMO, A. A. Serviço do prontuário do paciente: organização e técnica. São Paulo: Centro São Camilo de Desenvolvimento em Administração da Saúde, 1991. p. 245-321.

NAVAES, M. A.; MACHIAVELLI, J. L.; PATRÍCIO, C. M. O prontuário eletrônico do paciente no sistema de saúde brasileiro: uma realidade para os médicos? Scientia Medica, Porto Alegre, v. 21, n. 3, p. 121-131, 2011.

NOVAES, H. M. D. A evolução do registro médico. In: MASSAD, E.; MARIN, H. F.; AZEVEDO NETO, R. S. O prontuário eletrônico do paciente na assistência, informação e conhecimento médico. Sáo Paulo: Editora do Autor, 2003. p. 39-46.

PANZERI, C. S. B. A Prática da documentação clínica sob a ótica de Terapeutas Ocupacionais. 2013. 116 f. Dissertação (Mestrado em Terapia Ocupacional) - Universidade Federal de São Carlos, São Carlos, 2013.

PERINCHIEF, J. M. Controle dos serviços de Terapia Ocupacional. In: NEISTADT, M. E.; CREPEAU, E. B. Willard \& Spackman: Terapia Ocupacional. Rio de Janeiro: Guanabara Koogan, 2002. p. 722-738.

PERINCHIEF, J. M. Documentación y administración de losservicios de terapia ocupacional. In: CREPEAU, E. B.; COHN, E.S.; SCHELL, B. A. B. Willard \& Spackman: Terapia Ocupacional. Buenos Aires: Guanabara Koogan, 2008. p. 897-905.

POSSARI, J. F. Prontuário do paciente. In: POSSARI, J. F. Prontuário do paciente e os registros de enfermagem. São Paulo: Iátria, 2007. p. 17-34.

RADOMSKI, M. V. Planejamento, orientação e documentação da terapia. In: TROMBLY, C. A.; RADOMSKI, M. V. Terapia Ocupacional para disfunçóes físicas. São Paulo: Santos Editora, 2005. p. 443-461.

RICARTE, I. L. M.; GALVÃO, M, C, B. Prontuário do paciente. São Paulo: Guanabara Koogan, 2012.

SAMES, K. M. Documenting Occupational Therapy practice. Upper Saddle River: Prentice Hall, 2005.

SAMPIERE, R. H.; COLLADO, C. H.; LUCIO, P. B. Metodologia de pesquisa. São Paulo: McGraw-Hill, 2006.

SILVA, F.; TAVARES-NETO, J. Avaliação dos prontuários médicos de hospitais de ensino do Brasil. Revista Brasileira de Educação Médica, Rio de Janeiro, v. 31, n. 2, p. 113-126, 2007.

SLEE, V.; SLEE, D.; SCHMIDT, H. J. The endangered medical record: ensuring its integrity in the age of informatics. Saint Paul: Tringa Press, 2000.

VASCONCELLOS, M. M.; GRIBEL, E. B.; MORAES, I. H. S. Registros em saúde: avaliação da qualidade do prontuário do paciente na atenção básica. Cadernos de Saúde Pública, Rio de Janeiro, v. 24, n. SE 1, p. $173-$ 182, 2008. 


\section{Contribuição dos Autores}

Débora Cristina Pelissari: concepção do texto, coleta de dados, organização de fontes e análises. Marina Silveira Palhares: orientação da pesquisa e revisão do texto. Todos as autoras aprovaram a versão final do artigo.

\section{Notas}

${ }^{1}$ O material consiste em dados parciais da Dissertaçáo de Mestrado: "O registro em prontuários pelo Terapeuta Ocupacional em um ambulatório infantojuvenil”, realizada no Programa de Pós-Graduação em Terapia Ocupacional- PPGTO da Universidade Federal de São Carlos, sendo aprovada pelo Comitê de Ética da mesma instituiçáo mediante parecer n. ${ }^{\circ}$ 191.752.

${ }^{2}$ Informação recolhida com uma supervisora da Terapia Ocupacional.

${ }^{3}$ Trata-se de um checklist desenvolvido pela Pesquisadora Carla Benevides, sob supervisão da Prof. ${ }^{a}$ Dr. ${ }^{a}$ Marina S. Palhares, vinculado à Dissertação de Mestrado. 